\title{
Spatial Autocorrelation Analysis of Natuna's Capture Fisheries Production through Moran's I and LISA Indices
}

\author{
Gusrizal $^{1}$, Adji Suradji Muhammad ${ }^{2}$, Rodi Wahyudi ${ }^{3}$, Rado Yendra ${ }^{4}$, Ady Muzwardi ${ }^{5}$ \\ $\left\{{ }^{1}\right.$ gusrizal@sm-performa.co.id, ${ }^{2}$.suradji@umrah.ac.id, ${ }^{3}$ rodi.wahyudi@uin-suska.ac.id, ${ }^{4}$ rado yendra@uin- \\ suska.ac.id, $\underline{\text { ady_muzwardi@umrah.ac.id }\}}$
}

\begin{abstract}
${ }^{1}$ Sinergi Multi Performa Consultant, Tanjungpinang, Kepulauan Riau, ${ }^{2}$ Raja Ali Haji Maritime University, ${ }^{3}$ Universitas Islam Negeri Sultan Syarif Kasim, ${ }^{4}$ Universitas Islam Negeri Sultan Syarif Kasim, ${ }^{5}$ Raja Ali Haji Maritime University
\end{abstract}

\begin{abstract}
The Natuna Regency has a great potential for blue economy development in the form of capture fisheries. Currently, only a small part of the potential is actualized and contributes to the regional economy. This study aims to study the spatial aspects of capture fisheries production in the Natuna Regency. Two indices, namely the Moran's I and LISA indices were used to examine the presence of autocorrelation in 15 districts in the Natuna Regency in terms of capture fisheries production. Results showed that there was no spatial autocorrelation on a global scale (Moran's I), while on a local scale (LISA), it is indicated that there were clusters in several districts. It was also found that Bunguran Barat District has great potential for capture fisheries. The result of this study is expected to contribute to the development of the Natuna capture fisheries thus increasing its contribution to economic development.
\end{abstract}

Keywords: Natuna Regency, Capture Fisheries, Spatial Auto correlation, Moran's I, LISA

\section{Introduction}

Natuna Regency is an archipelago situated in the border area of the Riau Island Province. It has a great potential for economic growth from blue economy resources, especially fisheries. Insight from The 2020's Gross Regional Domestic Product (GRDP) of Natuna Regency by Industry [1], the fisheries sector contributed up to $8.11 \%$ of GRDP. The sectoral contribution to the GRDP of the Natuna Regency is still dominated by the mining and quarrying sector at $73.30 \%$. To date, the mining sector has not been able to bring a multiplier impact that can encourage economic development in the Natuna Regency. Therefore, the Natuna Regency needs to find alternative sources of sustainable growth, especially by optimizing renewable resources [2]. Optimal utilization of fishery resources should be able to increase the role of the fisheries sector in the economy of the Natuna Regency. Consequently, the Economic and Finance Bureau, Regional Secretary Office of the Natuna Regency initiated research on capture fisheries production, focused on the production of capture fishery in the Natuna District. The objective of this research is to 
understand all the variables involved in the capture fisheries production. The research of this paper focuses on the variable of capture fisheries in terms of geographical location.

This study will examine a spatial analysis namely spatial autocorrelation on Natuna's capture fisheries production data. The study of autocorrelation is important because: (a) its presence is considered an indication that something interesting in the distribution of map values requires further investigation to understand, and (b) the presence of spatial autocorrelation indicates information redundancy and has important implications for the spatial data analysis [3].

With this study, we hope that the government of the Natuna Regency will have a better understanding of spatial factors in the capture fisheries production. We believe that with this knowledge, the fisheries sector can be a driving force for the economic development of the Natuna Regency.

\section{Natuna's Capture Fisheries at a Glance}

The Natuna Regency is located in the State Fisheries Management Area of the Republic of Indonesia (WPP - RI) 711 which includes the Karimata Strait, the Natuna Sea, and the North Natuna Sea (Figure 1(i)). Based on the Decree of the Minister of Maritime Affairs and Fisheries Number 47/Kepmen-KP/2016 concerning Estimation of the Potential Amount of Allowed Catch, and the Level of Utilization of Fish Resources in the State Fisheries Management Area of the Republic of Indonesia (WPP-RI), WPP-RI 711 there is a sustainable potential of 1,143 .341 tons of fish per year.

Meanwhile, the utilization of capture fisheries production in the Natuna Regency in 2018 was $86,141.74$ tons, or only $7.53 \%$ of the sustainable potential (Natuna Regency Marine and Fisheries Office 2019). The potential of capture fisheries resources in the Natuna Regency is divided into two types, namely pelagic and demersal fish. Figure 1(ii) presents the distribution zones of the two fishery resources in the Natuna Regency. The resources of pelagic fish (including squid) are fish species in which the majority of their life cycle is on the surface or near the surface of the waters, with the characteristics: forming a large flock and migrating far with fast movement and activities. The most common small pelagic fish resources include mackerel scad, chub mackerel, scad, sardinella, sardinella lemuru, anchovy, and flyingfish. Moreover, large pelagic fish include tuna, skipjack, tuna mackerel, Spanish mackerel, swordfish, marlin, and sailfish.

The demersal fish (including reef fish) are a type of fish that most of their life on or near the bottom of the water. Continental shelf waters with relatively flat bottoms are usually demersal fishing grounds. The main characteristics of this fish group includes: forming a small flock and not travelling very far with a relatively low level of movement and activity. The most common demersal fish known to the public include red snapper, white pomfret, ariid catfish, goatfish, croacer, hairtail, lizardfish and ponyfish. 
(i)

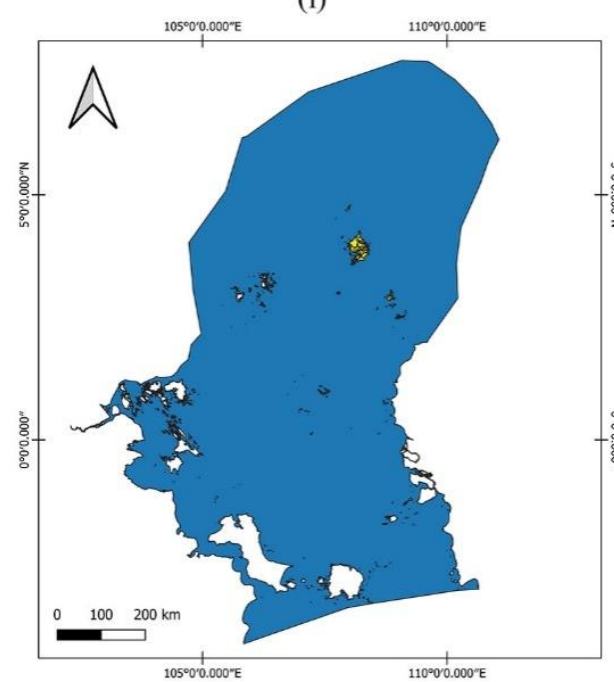

Figure 1.The location of the Natuna Regency (yellow color) in WP RI 711 for (i), and the subzone of capture fisheries for (ii).

\section{Data and Methods}

\subsection{Data}

The data used is taken from capture fisheries production data from each district in the Natuna Regency. Administratively, the Natuna Regency consists of 15 districts, namely; Bunguran Barat, Bunguran Batubi, Bunguran Selatan, Bunguran Tengah, Bunguran Timur, Bunguran Timur Laut, Bunguran Utara, Midai, Pulau Laut, Pulau Tiga, Pulau Tiga Barat, Serasan, Serasan Timur, Midai, Suak Midai, and Subi. Figure 2 presents the location of the fifteen districts. It can be seen that several districts such as Pulau Laut, Midai, Suak Midai, Subi, Serasan, and Serasan Timur are quite far from the main island of Bunguran. The capture fishery production data in the 15 districts are presented in Table 1, i.e.: data of the years 2018 and 2019. The 2018 data was chosen because before 2018 the division of new districts had not taken place, while 2019 was also chosen as a comparison and to make the analysis are more objective. 




Figure 2.The division of districts in the Natuna Regency

Table 1. Capture Fisheries Production in the Natuna Regency in 2018 and 2019.

\begin{tabular}{clrr}
\hline DISTRICT & \multicolumn{2}{c}{ District } & \multicolumn{2}{c}{ Production (in Tons) } \\
NUMBER & \multicolumn{1}{c}{ NAME } & \multicolumn{1}{c}{2019} \\
\hline 1 & BUNGURAN BARAT & 18,942 & 26,020 \\
2 & BUNGURAN BATUBI & 425 & 889 \\
3 & BUNGURAN SELATAN & 6,206 & 7,358 \\
4 & BUNGURAN TENGAH & 558 & 715 \\
5 & BUNGURAN TIMUR & 8,417 & 6,648 \\
6 & BUNGURAN TIMUR LAUT & 4,523 & 8,584 \\
7 & BUNGURAN UTARA & 1,271 & 3,535 \\
8 & MIDAI & 5,702 & 4,142 \\
9 & PULAU LAUT & 907 & 2,690 \\
10 & PULAU TIGA & 3,915 & 4,701 \\
11 & PULAU TIGA BARAT & 1,585 & 4,863 \\
12 & SERASAN & 12,028 & 10,714 \\
\hline
\end{tabular}




\begin{tabular}{rlrr}
\hline 13 & SERASAN TIMUR & 6,125 & 6,730 \\
14 & SUAK MIDAI & 824 & 2,033 \\
15 & SUBI & 15,820 & 15,258 \\
& TOTAL & 87,248 & 104,880 \\
\hline
\end{tabular}

\subsection{Methods}

Two methods were used in analyzing whether there is a spatial autocorrelation between each district in terms of producing capture fisheries in the Natuna Regency.

Visual Assessment. With this method, the capture fisheries production in the Natuna Regency will be plotted on the administrative map of each district. This action will be carried out with the QGIS[4] software on the 2018 and 2019 data. So, visually we will be able to see if a clustering pattern occurs on the capture fisheries production data [5].

Spatial Autocorrelation Indices. Spatial autocorrelation is a technique in spatial analysis to measure the similarity of attribute values in a space[6]. If there is a systematic pattern in the attribute values, then there is a spatial autocorrelation. The existence of spatial autocorrelation indicates that the attribute value in a certain area is related to the attribute value in other areas that are located closely to each other (neighbors). The neighborhood is expected to reflect a high degree of close area dependence (spatial) when compared to other areas that are far apart. Spatial autocorrelation is measured through two indices, namely the global and local autocorrelation indexes[7].

Moran's $I$ index is the most used indicator of global spatial autocorrelation. It was initiated by Moran[8] and popularized by Cliff and Ord[9]. The Moran's I is a cross-product between the variable and its spatial lag. Where the variable is expressed by the deviation from its mean value. Thus, the Moran's I can be expressed by:

$$
I=\frac{\sum_{i=1}^{n} \sum_{j=1}^{n} w_{i j}\left(x_{i}-\bar{x}\right)\left(x_{j}-\bar{x}\right)}{\sum_{i=1}^{n}\left(x_{i}-\bar{x}\right)^{2}} \quad \text { Equation } 1
$$

Where:

$x_{i}=$ variable's data at a location $i(i=1,2, \ldots, \mathrm{n})$

$x_{i}=$ variable's data at a location $j(j=1,2, \ldots, \mathrm{n})$

$\bar{x}=$ mean of variable $x$

$w=$ weight matrix

$n=$ number of observation

Moran's I can also be used for automatic identification of autocorrelation coefficients and the local autocorrelation of spatial correlation in each area. A higher local value of Moran's $I$ provides 
information that adjacent areas have almost the same value or form a clustered distribution. The formula of local Moran's $I$, usually named Local Indicator of Spatial Autocorrelation (LISA) [10], is expressed as in equation 2 below:

$$
I_{i}=z_{i} \sum_{i=1}^{n} w_{i j} z_{j}
$$

Equation 2

With $z_{i}=\frac{\left(x_{i}-\bar{x}\right)}{\sigma_{x}}$ and $z_{j}=\frac{\left(x_{j}-\bar{x}\right)}{\sigma_{x}}$, and $\sigma_{x}$ is the standard deviation of $x$.

\section{$4 \quad$ Results and Discussions}

\subsection{Visual Assessment Results}

Capture fisheries production results in 2018 and 2019 were mapped on the district layer of the Natuna Regency (Figure 3). If we look at Figure 3 and Table 1, it can be seen that the spatial pattern in the map is figured randomly. Thus, we need to perform deep analysis to check whether a spatial autocorrelation occurs in this data.

(ii)

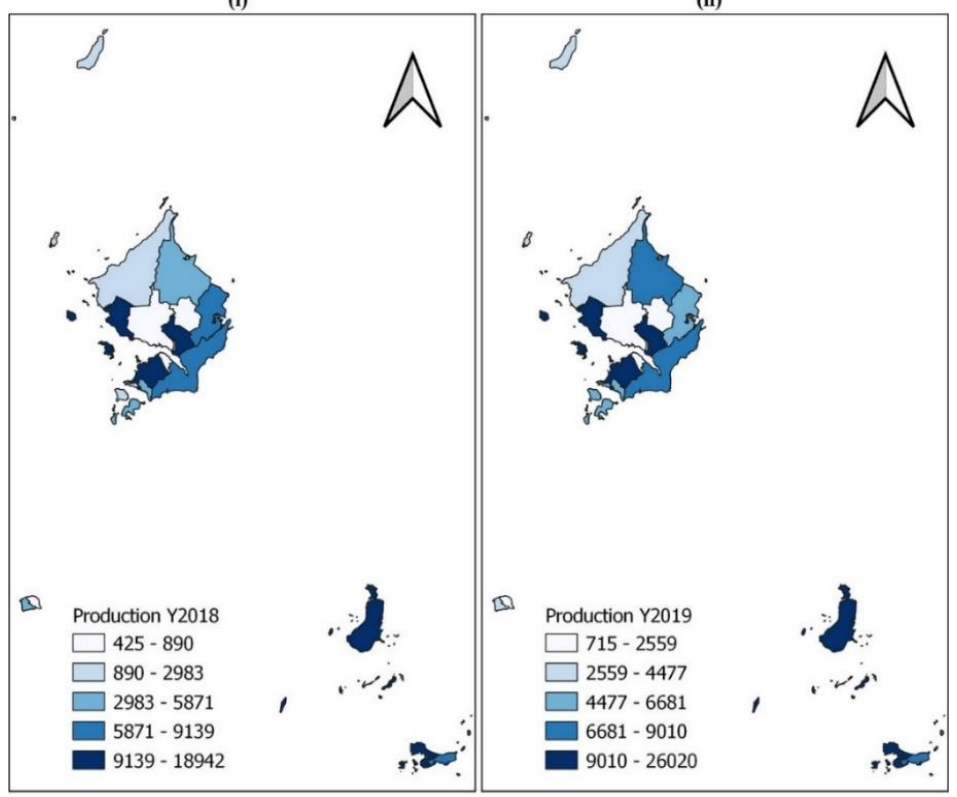

Figure 3.Natuna's Capture Production of Year 2018 for (i) and 2019 (ii) 


\subsection{Global Autocorrelation (Moran's I)}

To calculate the Moran's $I$ index, we need to find the weighted matrix. Before looking for a weighted matrix, the researchers need to model spatial neighbors. In general, there are two methods for doing spatial neighbors modeling, namely contiguity-based and distance-based. The contiguity-based method cannot be used in this study because the Natuna Regency has several districts separated on different islands. Additionally, some of the districts do not have any contiguous neighbors, such as Pulau Laut and Subi.

For this reason, the researchers need to find the cut-off distance from a neighborhood and how many average links are owned by one district. The calculation of the cut-off distance from all districts is presented in Table 2. The results of Table 2 show that the farthest distance between the two districts is $76,125 \mathrm{~km}$. Based on this value, we will round up the farthest distance between the two districts; $77 \mathrm{~km}$.

Table 2. Summary of the cut-off distance calculation (in km)

\begin{tabular}{llllll}
\hline Min & $1^{\text {st }} \mathrm{Qu}$ & Median & Mean & $3^{\text {rd }} \mathrm{Qu}$ & 'Max \\
\hline 2.780 & 6.456 & 8.096 & 16.032 & 14.736 & 76.125 \\
\hline
\end{tabular}

Furthermore, based on the value of the farthest distance, we obtained a weight matrix based on the fixed distance method (Table 3). From Table 3, we found that the average number of links (neighbors) for one district is 5.6 (rounded up to 6). From the findings in Table 3, we created a weight matrix based on the adaptive distance weight matrix (6 neighbors). Figure 4 illustrates the spatial neighbors modeling for (i) based on the Fixed Distance Weight (FDW) and (ii) based on the Adaptive Distance Weight (ADW).

Table 3. Fixed Distance Weight Matrix Summary

Neighbors list objects

Number of regions: 15

Number of nonzero links: 84

Percentage nonzero weights: 37.33333

Average number of links: 5.6 
(i)

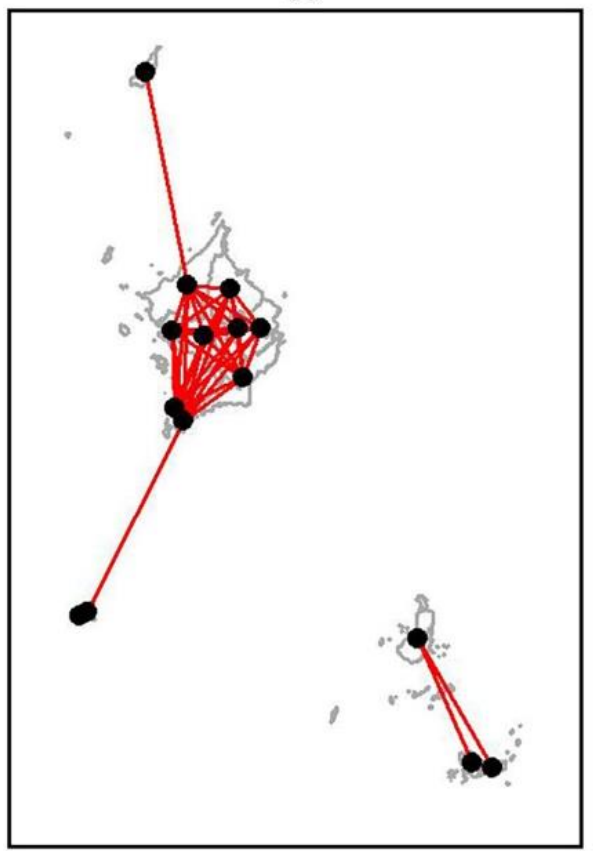

(ii)

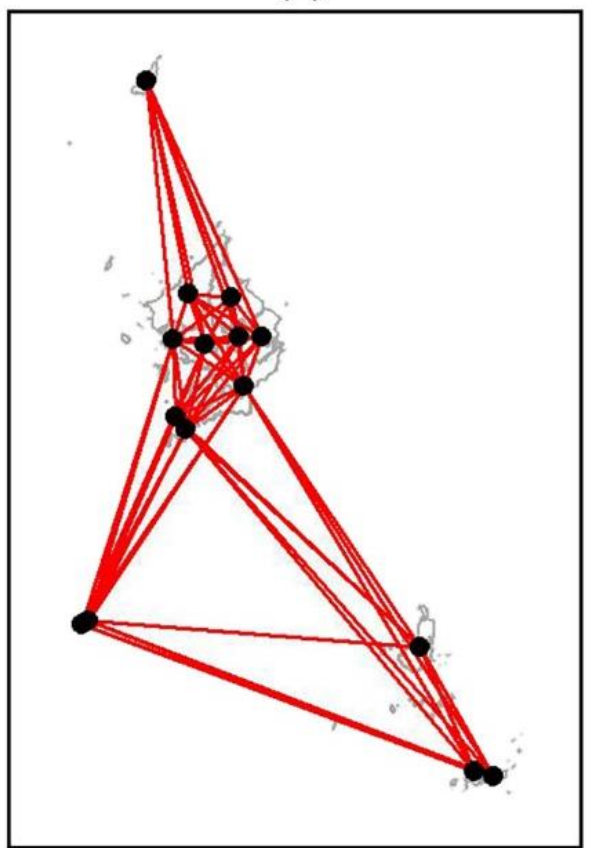

Figure 4. Distance-based neighbors for (i) within $77 \mathrm{~km}$ of neighbors (FDW), and (ii) for six nearest neighbors (ADW).

To identify whether there is a spatial autocorrelation or not, the Moran Index significance test was conducted. The hypothesis test for the Moran I index is as follows:

- Hypothesis

$\mathrm{H}_{0}$ : There is no spatial autocorrelation

$\mathrm{H}_{1}$ : There is a spatial autocorrelation

- $\quad$ Significance level $=\alpha=5 \%$

- $\quad$ Statistic test: $Z(I)=\frac{I-E(I)}{\sqrt{\operatorname{Var}(I)}}$

With $E(I)=$ expected value of $I$, and $\operatorname{Var}(I)=$ Variance of $I$

This test will be rejected ifH $H_{0}$ if $|Z(I)|>Z \alpha_{/ 2}$. Table 4 shows the $Z(I)$ values of all Moran's calculations mentioned above.

Table 4. Summary of Z(I) for each of Moran'sICalculation

\begin{tabular}{lrrrr}
\hline & 2018 FDW & 2019 FDW & 2018 ADW & 2019 ADW \\
\hline$I$ & 0.14686712 & 0.0246 & -0.1379 & -0.167 \\
$E(I)$ & -0.0714286 & -0.0714 & -0.0714 & -0.0714 \\
$\operatorname{Var}(I)$ & 0.02868521 & 0.02079 & 0.00612 & 0.00495 \\
$Z(I)$ & 1.288890861 & 0.665995 & -0.84971 & -1.35882 \\
\hline
\end{tabular}


The value of $Z \alpha_{\alpha / 2}$ for $\alpha=5 \%$ is 1,96 (Table of Normal Distribution). To reject the $\mathrm{H}_{0}$, the $|Z(I)|$ values in Table 4 should be more than 1.96. However, it can be seen that all values of $|Z(I)|$ are lower than 1.96. Therefore, the $\mathrm{H}_{0}$ hypothesis is accepted and indicates, in general that there is no spatial autocorrelation of capture fisheries production between each district in Natuna.

\subsection{Local Autocorrelation (LISA)}

The results of the LISA index obtained using the $\mathbf{R}$ package spdep[11] are listed in Table 5 (red values indicate negative numbers). It can be seen that only the Bunguran Barat District (district number 1) has a value greater than $1.96(\alpha=5 \%)$. This indicates that there is a possibility of a cluster pattern formed around the Bunguran Barat District. Meanwhile, other districts have values less than 1.96 (please refer to Table 1 for district names). To refine the results of the local cluster analysis, the researchers drew cluster maps of Natuna's capture fisheries production for 2018 and 2019 and divided it into quadrants. According Anselin[12], the quadrants are as following:

- Quadrant I, HH (High-High) indicates that in the area that have high observation values are surrounded by areas that have high observation values.

- Quadrant II, LH (Low-High) indicates that the area that have low observation values are surrounded by areas that have high observation values.

- Quadrant III, LL (Low-low) indicates that the area that have low observation values are surrounded by areas that have low observation values.

- Quadrant IV, HL (High-Low) indicates that the area that have high observation values are surrounded by areas that have low observation values.

The cluster map is drawn using the Geoda software [13] as shown in Figure 5. From Figure 5 we can see that three districts, namely: Bunguran Barat, Subi, and Serasan are in the high-high quadrant, while six districts, namely: Pulau Laut, Bunguran Utara, Bunguran Batubi, Bunguran Tengah, Pulau Tiga Barat, and Suak Midai are in the low - low quadrant. Moreover, referring to Figure 5(ii), we can see that only Bunguran Barat is in the high - high quadrant. The low-low quadrant is filled with 5 districts the same as in Figure 5(i) minus the Pulau Tiga Barat district. These findings indicate that there is some positive autocorrelation in several of Natuna's Districts. These findings also emphasize the importance of the Bunguran Barat District in terms of capture fisheries.

Table 5. LISA Index values of Natuna's Capture Fisheries for the Years 2018 and 2019

\begin{tabular}{ccccccccccc}
\hline District & \multicolumn{2}{c}{$I i$} & \multicolumn{2}{c}{$E($ Ii $)$} & \multicolumn{2}{c}{$\operatorname{Var}($ Ii $)$} & \multicolumn{2}{c}{$Z(I i)$} & \multicolumn{2}{c}{$\operatorname{Pr}(z>0)$} \\
Number & 2018 & 2019 & 2018 & 2019 & 2018 & 2019 & 2018 & 2019 & 2018 & 2019 \\
\hline 1 & 1.427 & 1.276 & 0.071 & 0.071 & 0.096 & 0.089 & 4.367 & 4.048 & 1.000 & 1.000 \\
2 & 0.081 & 0.039 & 0.071 & 0.071 & 0.096 & 0.089 & 0.030 & 0.109 & 0.512 & 0.457 \\
3 & 0.013 & 0.044 & 0.071 & 0.071 & 0.096 & 0.089 & 0.190 & 0.094 & 0.425 & 0.463 \\
\hline
\end{tabular}




\begin{tabular}{ccccccccccc}
\hline 4 & 0.002 & 0.003 & 0.071 & 0.071 & 0.096 & 0.089 & 0.223 & 0.250 & 0.412 & 0.401 \\
5 & 0.123 & 0.027 & 0.071 & 0.071 & 0.096 & 0.089 & 0.625 & 0.149 & 0.266 & 0.441 \\
6 & 0.020 & 0.080 & 0.071 & 0.071 & 0.096 & 0.089 & 0.295 & 0.029 & 0.384 & 0.512 \\
7 & 0.145 & 0.279 & 0.071 & 0.071 & 0.096 & 0.089 & 0.236 & 0.697 & 0.593 & 0.757 \\
8 & 0.050 & 0.125 & 0.071 & 0.071 & 0.096 & 0.089 & 0.069 & 0.180 & 0.473 & 0.572 \\
9 & 0.006 & 0.021 & 0.071 & 0.071 & 0.096 & 0.089 & 0.210 & 0.312 & 0.417 & 0.378 \\
10 & 0.101 & 0.120 & 0.071 & 0.071 & 0.096 & 0.089 & 0.097 & 0.162 & 0.538 & 0.564 \\
11 & 0.002 & 0.047 & 0.071 & 0.071 & 0.096 & 0.089 & 0.236 & 0.083 & 0.407 & 0.467 \\
12 & 0.041 & 0.007 & 0.071 & 0.071 & 0.096 & 0.089 & 0.097 & 0.215 & 0.461 & 0.415 \\
13 & 0.137 & 0.291 & 0.071 & 0.071 & 0.096 & 0.089 & 0.212 & 0.739 & 0.584 & 0.770 \\
14 & 0.016 & 0.002 & 0.071 & 0.071 & 0.096 & 0.089 & 0.281 & 0.232 & 0.389 & 0.408 \\
15 & 0.226 & 0.192 & 0.071 & 0.071 & 0.096 & 0.089 & 0.496 & 0.406 & 0.690 & 0.658 \\
\hline
\end{tabular}

(i)

(ii)

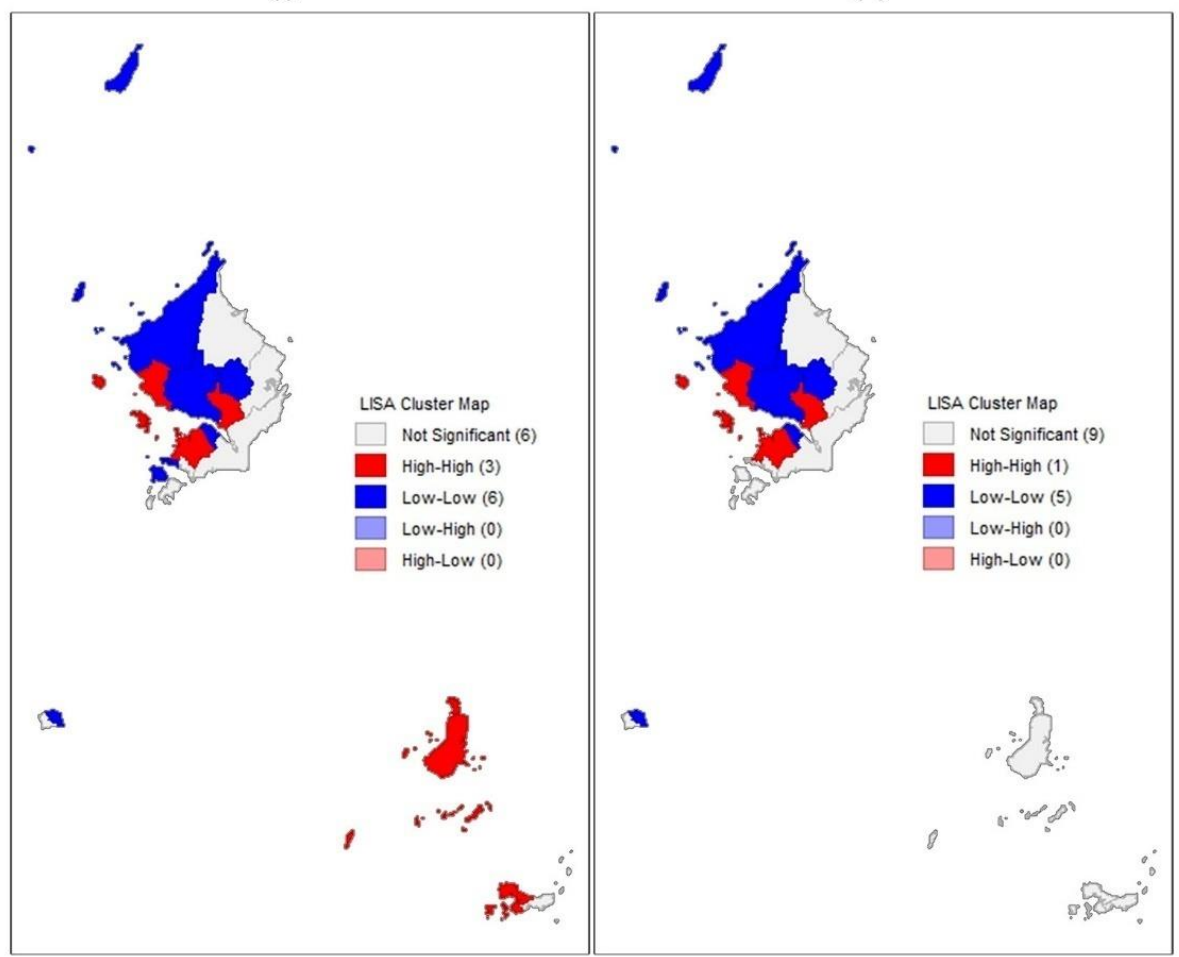

Figure 5. LISACluster Map of Natuna's Capture Fisheries Production for 2018 (i) and 2019 (ii). 


\section{Conclusion and Future Works}

From the above findings, the researchers conclude that:

1. In general, no spatial autocorrelation is found in the data of Natuna's capture fisheries production, as shown by the values $Z(I)$ of the global autocorrelation (Moran's $I$ ) index.

2. There is some form of spatial clusters occurring between some capture fishery producing districts. This is concluded through the LISA index value and spatial clustering images. We also found that Bunguran Barat District is the center of spatial clustering in the highhigh quadrant. This means that the Bunguran Barat District can become the center of capture fisheries production in the Natuna Regency.

3. Future research is needed to examine the determinant factors of Natuna's capture fisheries production values by employing econometrics models.

Optimal utilization of fishery resources should be able to increase the role of the fisheries sector in the economy of the Natuna Regency. With this study, we hope that the government of the Natuna Regency will have a better understanding of spatial factors in the capture fisheries production. We believe that with this knowledge, the fisheries sector can be a driving force for the economic development of the Natuna Regency

Acknowledgment. Our sincere gratitude to the Fisheries Department of the Natuna Regency for their data support and fruitful discussion. This research was funded by Bureau Economic and Finance, Office of Regional Secretary, Natuna Regency with contract number 500/EKON $\mathrm{SDA} / 109$.

\section{References}

[1] Office of Statistical Beraeu of Natuna Regency. Gross Regional Domestic Product of Natuna Regency by Industry 2016 - 2020. 2020.

[2] Anggraeni M, Rustiadi E, Yulianto G. Peranan Sektor Perikanan Terhadap Perekonomian Kabupaten Natuna. J Kebijak Sos Ekon Kelaut Dan Perikan 2020;10:11. https://doi.org/10.15578/jksekp.v10i1.8155.

[3] Haining RP. Spatial Autocorrelation. Int Encycl Soc Behav Sci 2001:14763-8. https://doi.org/10.1016/B0-08-043076-7/02511-0.

[4] QGIS Development Team. QGIS Geographic Information System 2021.

[5] Newell R, Canessa R. Picturing a place by the sea: Geovisualizations as place-based tools for collaborative coastal management. Ocean Coast Manag 2017;141:29-42. https://doi.org/10.1016/J.OCECOAMAN.2017.03.002.

[6] Anselin L. Spatial econometrics: methods and models. Kluwer Academic Publishers; 1988.

[7] Bivand RS, Wong DWS. Comparing implementations of global and local indicators of spatial association. TEST 2018273 2018;27:716-48. https://doi.org/10.1007/S11749-0180599-X.

[8] Moran PAP. Notes on Continuous Stochastic Phenomena. Biometrika 1950;37:17. 
https://doi.org/10.2307/2332142.

[9] Fischer MM, Getis A. Handbook of Spatial Analysis. Igarss 2014 2010:801.

[10] Anselin L. Local indicators of spatial association-LISA. Geogr Anal 1995;27:93-115. https://doi.org/10.1111/j.1538-4632.1995.tb00338.x.

[11] Bivand RS, Wong DWS. Comparing implementations of global and local indicators of spatial association. TEST 2018273 2018;27:716-48. https://doi.org/10.1007/S11749-0180599-X.

[12] Anselin L. The Moran scatterplot as an ESDA tool to assess local instability in spatial association. Spat Anal Perspect GIS 2019:111-26. https://doi.org/10.1201/9780203739051-8.

[13] Anselin L, Syabri I, Kho Y. GeoDa: An Introduction to Spatial Data Analysis. Geogr Anal 2006;38:5-22. https://doi.org/https://doi.org/10.1111/j.0016-7363.2005.00671.x. 